\title{
Claudin-3 and occludin content in the glands of colonic mucosa devoid from fecal stream submitted to topical intervention with oil extract of Curcuma longa ${ }^{1}$
}

\author{
Carlos Augusto Real Martinez', Caled Jaoudat Kadri", Danilo Toshio Kanno'", Antônio José Tibúrcio \\ Alves Júnior'v , Cláudio Saddy Rodrigues Coyv, José Aires Pereiravi \\ 'PhD, Associate Professor, Postgraduate Program in Health Sciences, Universidade São Francisco (USF), Bragança Paulista- \\ SP, Brazil. Associate Professor, Department of Surgery, Universidade Estadual de Campinas (UNICAMP), Campinas-SP, Brazil. \\ Intellectual and scientific content of the study, manuscript writing, critical revision. \\ "PhD, Assistant Professor, School of Medicine, USF, Bragança Paulista-SP, Brazil. Acquisition and interpretation of data, technical \\ procedures. \\ I'Fellow Master degree, Postgraduate Program in Health Sciences, Bragança Paulista-SP, Brazil. Acquisition and interpretation \\ of data, technical procedures. \\ IVFellow Master degree, Postgraduate Program in Surgical Sciences, UNICAMP, Campinas-SP, Brazil. Acquisition and \\ interpretation of data, histological examinations, technical procedures. \\ ${ }^{\vee}$ PhD, Associate Professor, Head, Department of Surgery, UNICAMP, Campinas-SP, Brazil. Manuscript writing, critical revision. \\ VIPhD, Assistant Professor, Discipline of Pathology, School of Medicine, USF, Bragança Paulista-SP, Brazil. Acquisition and \\ interpretation of data, histological and immunohistochemical analysis.
}

\footnotetext{
Abstract

Purpose: To evaluate the inflammatory intensity and measure the tissue content of the proteins claudin-3 and occludin in the colonic mucosa without fecal stream submit to intervention with curcumin.

Methods: Thirty-six rats were submitted to a proximal colostomy and a distal mucous fistula and divided into two groups according to sacrifice to be performed two or four weeks. Each group was divided into three subgroups according daily application of enemas containing saline, curcumin at $50 \mathrm{mg} / \mathrm{kg} /$ day or $200 \mathrm{mg} / \mathrm{kg} /$ day. Colitis was diagnosed by histological analysis. Claudin-3 and occludin were determined by immunohistochemistry. The tissue content of claudin-3 and occludin were quantified by computer-assisted image analysis. MannWhitney, Student $t$ and ANOVA tests were used to analyze the results establishing the level of significance of $5 \%$ for both $(p<0.05)$.

Results: Curcumin at both concentrations reduces the inflammation and preserves the tissue content of the proteins claudin-3 and occludin, which was related to the concentration used and to the time of the intervention.

Conclusion: The application of enemas with curcumin reduces inflammation and preserves the tissue content of the proteins claudin- 3 and occludin in the colonic mucosa devoid from the fecal stream.

Key words: Colon. Colitis. Claudin-3. Occludin. Image Processing, Computer-Assisted. Curcuma. Rats.
} 


\section{Introduction}

Mechanical and immunological defense systems that form the epithelial barrier of the colonic mucosa confer important protection against bacterial translocation ${ }^{1}$. This defense system is formed by different structures, which act as mechanical barrier, and by cells of the immune system, which constitute an immunological barrier ${ }^{1-3}$. The mechanical protection are formed by the mucus that recover the intestinal epithelium, the cellular membranes of colonocytes, the mechanisms of intercellular junctions (IJs) and basal membrane $e^{4}$. In turn, the immunological protection is conferred by inflammatory response cells as well by antibodies, abundant in the intestinal wall. The main energy source for the maintenance of this complex system of defense comes from the regular supply of volatile fatty acids (VFAs) produced from the fermentation of dietary fiber ${ }^{5}$. VFAs, primarily acetate, propionate and butyrate, are organic acids produced within the colonic lumen by bacterial fermentation of undigested dietary carbohydrates.

Glotzer et al. ${ }^{6}$ demonstrated that the interruption of the supply of VFAs leads to the inflammatory process in the colonic mucosa derived from the fecal transit. The disease became known by different names as exclusion colitis, diversion colitis, disuse colitis and colitis of the derived colon (CDC). The modifications of the cellular metabolism by which the deficiency in the supply of VFAs leads to the CDC are still controversial ${ }^{4}$. Recently, it was shown that cells of the colonic mucosa without VFAs supply suffer modifications of the cellular respiratory chain responsible for production of energy resulting in the over production of oxygen free radicals (OFR) ${ }^{4}$. OFR are toxic to cells and to maintain the balance between production and neutralization, all human tissues have specific antioxidant defense systems mainly represented by the superoxide dismutase and glutathione peroxidase enzymatic systems? Meantime, the overproduction of OFR can trigger a pathological condition known as oxidative stress. In oxidative stress, the increase in the production of OFR, mainly hydroxyl radical $(\mathrm{OH})$ can react with constitute substances of the colonic epithelial mucosa causing breakdown of the different structural defense mechanisms of the colonic barrier allowing the bacterial infiltration of the internal environment ${ }^{4,7}$. Studies showed that over production of OFR reduce and modify the mucus layer that covers the colonic mucosa, causes lipid peroxidation of the cell membranes, break the proteins constituents of adherents junctions (AJs) and tight junctions (TJs) ${ }^{8-11}$. Experimentally it has been demonstrated that the rupture of the epithelial barrier are related to higher levels of OFR and the development of $\mathrm{CDC}^{9,10}$.

Several substances have been tested for the treatment of CDC. Most of these drugs exhibit anti-inflammatory and antioxidant effects reducing the epithelial inflammation and oxidative stress $\mathrm{s}^{1-3,12,13}$. Curcumin, the principal active principle present in the rhizome of Curcuma longa, has showed to be a promising substance for the treatment of different groups of inflammatory bowel disease (IBD) because it's anti-inflammatory and antioxidant properties ${ }^{14}$. Studies confirmed the benefits of oral curcumin administration in experimental models of chemical induced-colitis ${ }^{15-17}$. Clinical trials also confirmed the benefits of curcumin in patients with inflammatory bowel disease (IBD) and, in particular, those with ulcerative colitis $^{18,19}$. Among the several mechanisms proposed for the action of curcumin in these patients, the antioxidant effects of the substance have pride of place ${ }^{20}$.

Some studies have evaluated the therapeutic efficacy of curcumin in human or chemically-induced colitis model, to the best of our knowledge, only one study of 
our group studied the effects of curcumin in experimental models of $\mathrm{CDC}^{14,18-20}$. In this study, we showed that the daily application of enemas containing oily extract of curcumin improved the inflammation of the colonic mucosa and decreased the neutrophil infiltrate in colonic epithelium devoid from the fecal stream $^{20}$. No studies evaluated the effects of topical application of curcumin-containing enemas to protect against the damage of TJs in experimental models of CDC. When it was shown that oxidative stress can damage constituent proteins of TJs and curcumin has remarkable antioxidant activity, it is interesting to evaluate the effectiveness of the substance to preserve the tissue content of the claudin-3 and occludin, the main proteins constituents of the TJs in an experimental model of $C D C^{9,10}$. If curcumin is capable of preserving the TJs integrity and consequently reduce the damage of this important mechanism of intercellular adhesion, its low cost and bioavailability could make it interesting alternative for the treatment of CDC. Thus, the aim of the present study was to verify if the daily application of enemas containing oily extract of curcumin preserves the tissue content of the claudin-3 and occludin proteins in the colonic mucosa devoid of the fecal transit.

\section{- Methods}

This study was performed in accordance with the Brazilian Federal Law No. 11,794 and the guidelines of the Brazilian College for Animal Experimentation (COBEA). This experimental study was approved by the Research Ethics Committee, Universidade São Francisco, Bragança Paulista-SP, Brazil (Process №. 2211/07).

Thirty-six Wistar rats were divided into three groups with 12 rats in each. The first group received daily enemas containing saline. The second and third groups received daily enemas containing oily extract of curcumin (Sigma-Aldrich Corporation, St Louis, USA) at two different concentrations $(50 \mathrm{mg} / \mathrm{kg} /$ day and $200 \mathrm{mg} / \mathrm{kg} /$ day, respectively). In each group, six animals were sacrificed after two weeks and the other six after four weeks after the intervention.

\section{Surgical technique: diversion of the fecal stream}

The surgical methodology used for the induction of exclusion colitis has already been described in previous studies published by our group ${ }^{1-3}$. Briefly, all animals were placed under general anesthesia by intramuscular administration of $0.1 \mathrm{~mL} / 100 \mathrm{~g}$ of a $1: 1(\mathrm{v} / \mathrm{v})$ ketamine $(50 \mathrm{mg} / \mathrm{mL})$ and xylazine $(20 \mathrm{mg} / \mathrm{mL})$. The abdominal wall was open by a $5-\mathrm{cm}$ midline incision and the left colon $8 \mathrm{~cm}$ above of anal margin was sectioned and the cranial segment was exteriorized as a proximal colostomy. The distal segment of the sectioned left colon was catheterized with polyvinyl catheter and it was irrigated with saline until the effluent drained through the animal's anus no longer contained fecal material. After irrigation, the catheter was removed, and the distal segments of the colon was exteriorized as a distal colostomy. The abdominal incision was closed in two layers. During the postoperative period, the rats were maintained in individual cages without particular care for the stomas or abdominal incisions. Analgesia was improved by diluting dipyrone $(15 \mathrm{mg} / \mathrm{kg}$ ) into the water offered daily and antibiotic it's not used.

\section{Sample collection}

Upon completion of the intervention period, the rats were anesthetized as described above, and the midline incision was opened again. In both groups, specimens were taken from the colon without fecal stream subjected to irrigation with saline 
and oily extract of curcumin. The removed specimen with $4.0 \mathrm{~cm}$ of length was opened through the anti-mesenteric border fixed in a piece of cork and referred to histological and immunohistochemical techniques. The euthanasia was done by intracardiac injection of lethal dose of thiopental.

\section{Histological analysis}

The colon specimens for histological analysis were immersed in $10 \%$ neutral formalin buffer for 24h, dehydrated by exposure to increasing ethanol concentrations, and embedded in paraffin. Thereafter, sections of tissue were cut at $5 \mu \mathrm{m}$ was mounted on a glass slide, cleared, hydrated and stained with hematoxylin-eosin (HE) for evaluation of the presence of colitis. The slides were analyzed under an optical microscope (Nikon Inc., Tokyo, Japan) at a magnification of 200x. The slides prepared for both histology and immunohistochemistry (anti-claudin-3 and anti-occludin) were evaluated by a pathologist who was unaware of the objectives of the study.

Photomicrographs were taken with a digital video-capture camera (DS-Fi-50; Nikon Inc., Osaka, Japan) coupled to the microscope body. The presence of colitis in the colon segments devoid of the fecal stream was confirmed by the presence of two independent histological parameters: mucosal-submucosal neutrophil infiltration and presence of epithelial erosion or ulceration and classified in crosses (to $9+)$. The severity of the inflammation in the colonic mucosa devoid from the fecal stream was established in accordance with a previous used inflammatory grade scale ${ }^{2}$.

\section{Immunohistochemical staining}

For the immunoexpression study of claudin-3 and occludin proteins, we used standardized methodology adopted in other studies of our group and obeying the datasheet of the manufacturers of each of the primary antibodies ${ }^{9-11}$. As primary antibody, we used anti-claudin-3 monoclonal antibody (Ref. E-3834, Lot. 110520, Spring Bioscience, Pleasanton, CA, USA). The anti-claudin-3 primary antibody was mixed 1:50 in bovine serum albumin (1\%). The monoclonal antibody anti-occludin (Ref. E-17464, Lot. 111207S, Spring Bioscience, Pleasanton, CA, USA) was mixed 1:100 in bovine serum albumin (1\%). The slides were covered with approximately $100 \mu \mathrm{L}$ of these solutions and were incubated at $4^{\circ} \mathrm{C}$ for 24 hours. After exposure to the primary antibody, the slices were washed with PBS and incubated with a secondary antibody (Lot: H1011 Histofine Code: 414191N, Spring Bioscience, Pleasanton, CA, USA). After, they were incubated with the streptavidin-biotinperoxidase complex (ABC Staining System, Dako $A / S$, Glostrup, Denmark). The chromogenic reaction was developed with a freshly prepared solution of DAB (diaminobenzidine tetrahydrochloride, $10 \mathrm{mg}$ in $10 \mathrm{~mL}$ PBS), which was added to $3 \mathrm{~mL}$ of $\mathrm{H}_{2} \mathrm{O}_{2}$ five minutes before the end of the $A B C$ incubation. The slides were washed and counterstained with methyl green for one minute and washed again in distilled water. Next, the slides were dehydrated by immersion in crescent concentration of ethanol followed by xylene. Finally, they were mounted, labeled and kept in a horizontal position for 24 hours.

Immunostaining was considered positive when a diffuse brownish color with spots of varying intensity and homogeneous distribution in the apical or basolateral cellular membrane was observed. As recommended by the data-sheet of both primary antibodies used, a negative control was prepared without the addition of the primary antibody, and a positive control for claudin-3 and occludin was prepared using normal human small bowel tissue, which is known to be positive for both proteins. 
Image processing, computer-assisted

The tissue content of claudin-3 and occludin was quantified by means of computerized morphometry and was always performed in a focal field in which there were at least three complete and contiguous colonic glands. These images were analyzed using the NIS-Elements 3.1 software (Nikon Inc., Osaka, Japan). The software would transform the color intensity in number of pixels in each field selected. The pixel values were transformed into percentage of protein expressions by analyzed fields (\%/fields). The final value taken for each field measured in the colonic segments was the mean of the values found from evaluating three different fields.

\section{Statistical analysis}

The statistical analysis was performed by taking the significance level of $5 \%(p<0.05)$. The data from each colon segment analyzed, in each experimental group, were expressed as the mean value with the respective standard error, and were analyzed using the SPSS 13.0 for Windows statistical software. To compare the grade of inflammatory score among the different experimental subgroups, the nonparametric Mann-Whitney test was used. To compare the content of claudin-3 and occludin among the different experimental subgroups, Student's t test was used. To analyze the variance in the claudin- 3 and occludin tissue content among the different experimental groups, ANOVA was used.

\section{- Results}

Figure $1 A$ and $B$ show the colonic epithelium is segments devoid from the fecal stream submitted to daily application of enemas with saline and $200 \mathrm{mg} / \mathrm{kg} /$ day of curcumin for four weeks, respectively. In colon segments submitted to intervention with saline the epithelial surface resembled a "brush border", the colonic glands were dilated with large amounts of mucus in the goblet cells and inflammatory infiltrate between the colonic glands (Figure 1A). In a different way, the colonic mucosa submitted to intervention with oily extract of curcumin at concentration of $200 \mathrm{mg} / \mathrm{kg} /$ day the epithelial surface is regular, the goblet cells contain less mucus, and colonic epithelium with less neutrophils infiltration (Figure 1B).

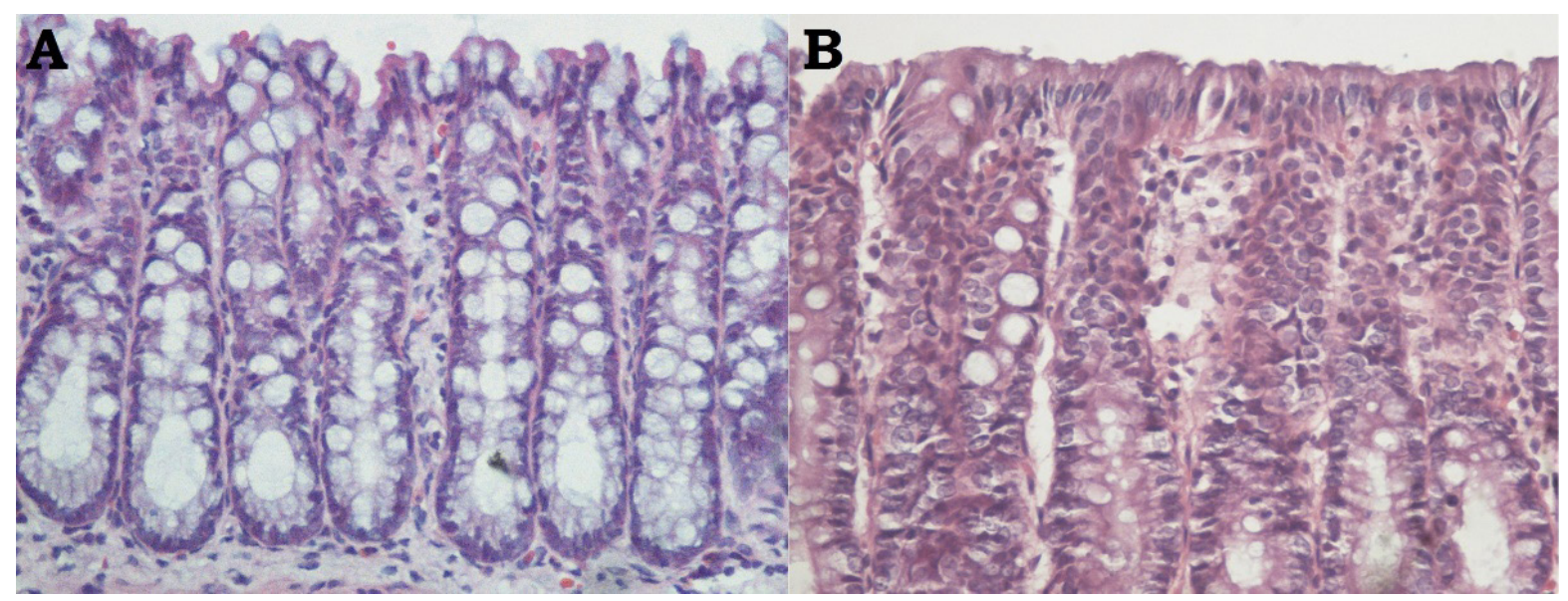

Figure 1 - Colonic mucosa: A) Colonic mucosa devoid from fecal stream submitted to intervention with saline with epithelial "brush border". B) Colonic mucosa devoid from the fecal stream submitted to intervention with curcumin at concentration of $200 \mathrm{mg} / \mathrm{kg} /$ day. The colonic mucosa is regular without epithelial erosion or ulcers (HE-x400). 
Figure 2 compares the inflammation grading scores for colon segments without fecal stream in different experimental groups. An increase in the inflammatory score was founded in colon segments without fecal stream submitted to intervention with saline when compared with animals submitted to intervention with curcumin independent of concentration applied.

Figure $3 A$ show the tissue expression of claudin-3 in colon segments devoid from the fecal transit submitted to intervention with saline for 4 weeks. Figure 3B show the tissue expression of claudin-3 in colon segments devoid from the fecal transit submitted to intervention with curcumin at concentration of $200 \mathrm{mg} / \mathrm{kg} /$ day for 4 weeks.

Figure 4 compares the tissue content of claudin-3 measured by computerized morphometry among colon segments submitted to intervention with saline, oily extract of curcumin at concentration of $50 \mathrm{mg}$ $/ \mathrm{kg} /$ day or $200 \mathrm{mg} / \mathrm{kg} /$ day for two or four weeks. We found an increase of the tissue content of claudin-3 in segments without fecal stream submitted to intervention with curcumin independent of the concentration utilized or time of intervention $(p<0.01)$.

Figure $5 \mathrm{~A}$ show the tissue expression of occludin in colon segments submitted to intervention with saline for 4 weeks. Figure $5 B$ show the tissue expression of occludin in colon segments devoid from the fecal transit submitted to intervention with curcumin at concentration of $200 \mathrm{mg} / \mathrm{kg} /$ day for 4 weeks.

Figure 6 compares the tissue content of occludin between colon segments submitted to intervention with saline, oily extract of curcumin (50 mg / kg/ day) or oily extract of curcumin (200 mg / kg/ day) for 2 or 4 weeks. We found an increase of the tissue content of occludin in segments without fecal stream submitted to intervention with curcumin independent of the concentration utilized or time of intervention $(p<0.01)$.

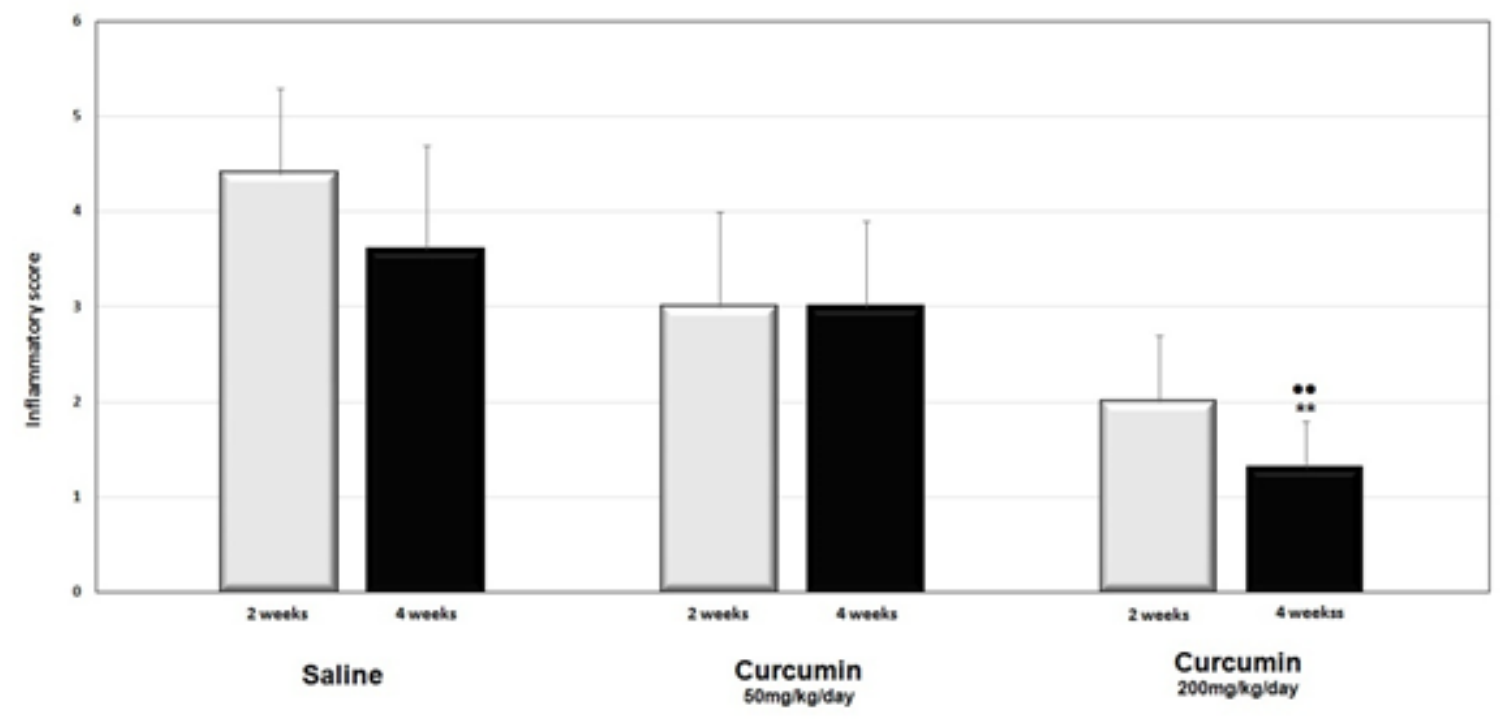

Figure 2 - Inflammation grading score in colon segments without fecal stream after irrigation with saline, curcumin (50 mg / kg /day) and curcumin ( $200 \mathrm{mg} / \mathrm{kg} /$ day) for 2 or 4 weeks. ${ }^{* *}=$ saline $\times$ curcumin $200 \mathrm{mg} / \mathrm{kg} /$ day, $\mathrm{p}<0.01 ;{ }^{\bullet}=$ curcumin $50 \mathrm{mg} / \mathrm{kg} /$ day $\times$ curcumin $200 \mathrm{mg} / \mathrm{kg} / \mathrm{day}$ for four weeks, $p<0.01)$. Mann-Whitney test. 


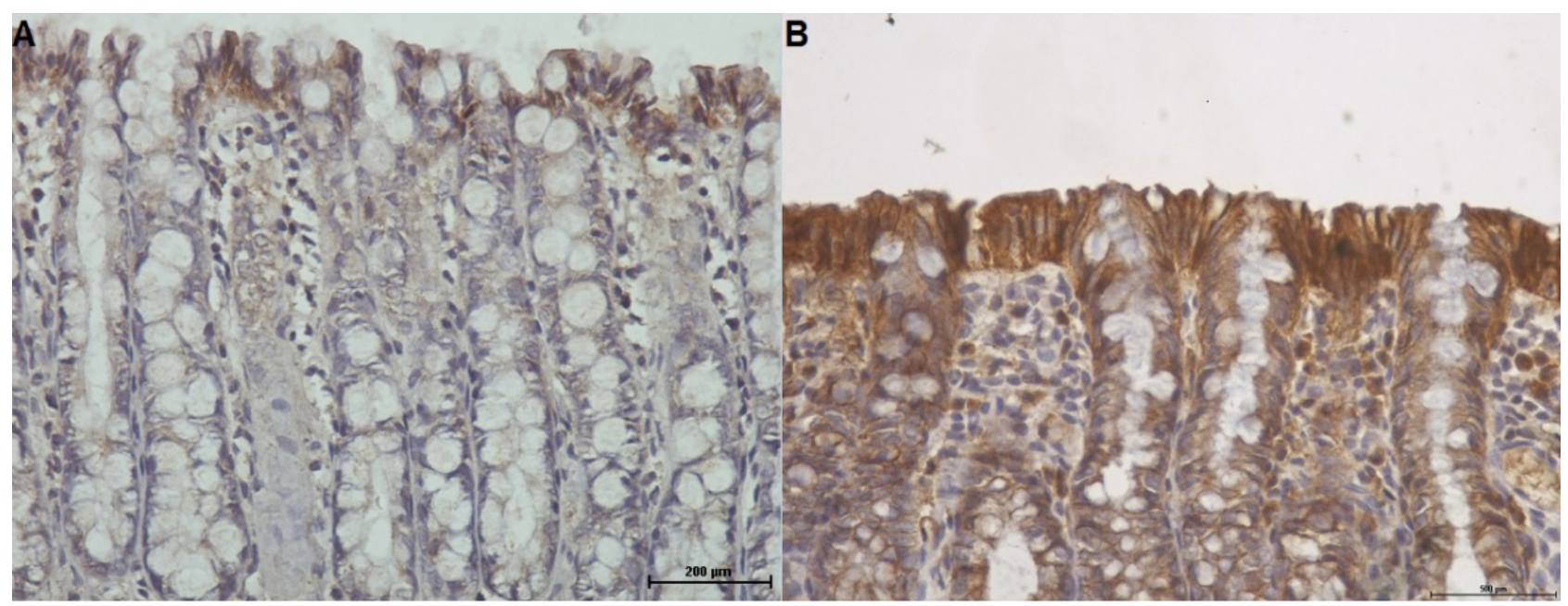

Figure 3 - Colonic mucosa: A) Colonic mucosa devoid from fecal stream submitted to intervention with saline. Less amount of claudin-3 presence at epithelium surface (IH anti-claudin-3-x400). B) Colonic mucosa devoid from the fecal stream submitted to intervention with curcumin at concentration of $200 \mathrm{mg} / \mathrm{kg} /$ day with large of claudin 3 in apical and basolateral membranes of the cells of the colonic epithelium $(200 \mathrm{mg} / \mathrm{kg} / \mathrm{day})$ (HE-x400).

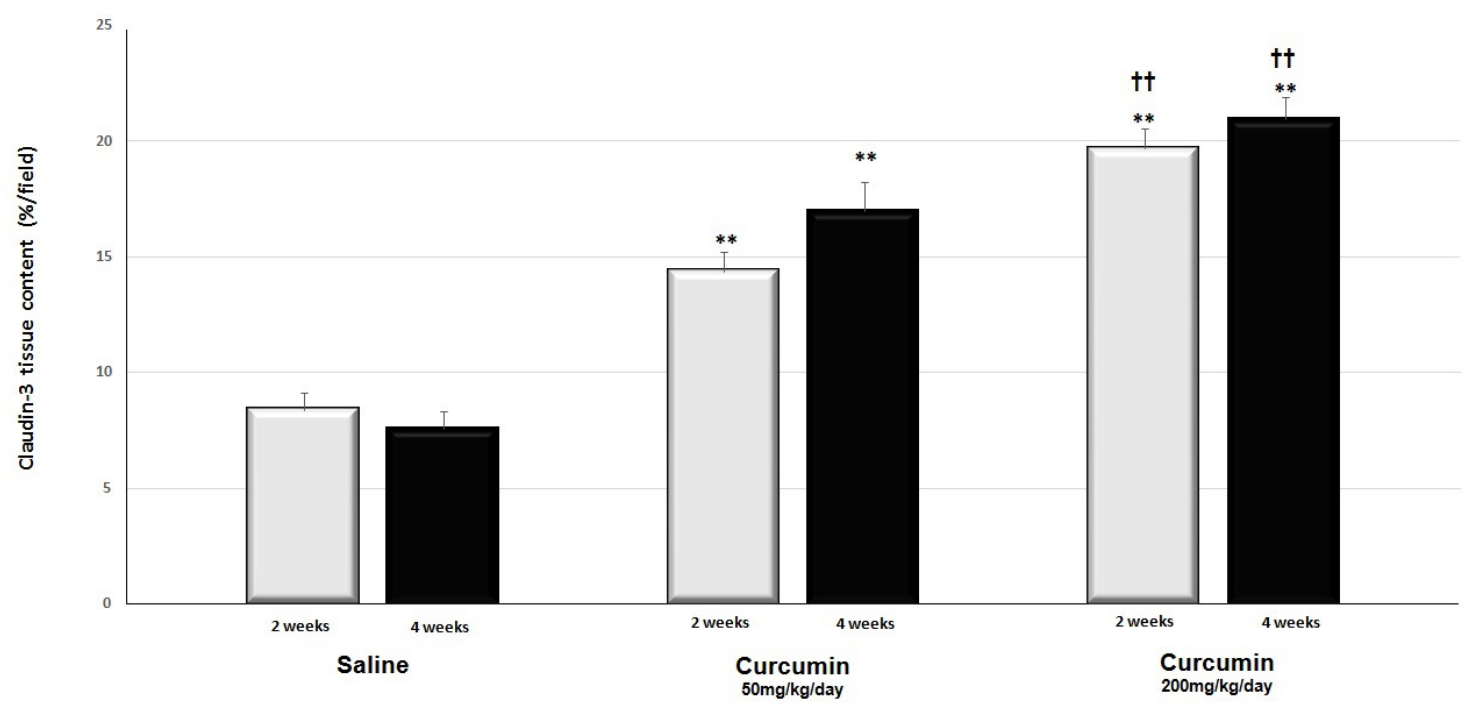

Figure 4 - Tissue content of claudin-3 in colon segments without fecal stream after irrigation with saline, curcumin $(50 \mathrm{mg} / \mathrm{kg} / \mathrm{day})$ and curcumin $(200 \mathrm{mg} / \mathrm{kg} /$ day) for 2 or 4 weeks. (** = saline $\times$ curcumin 50 $\mathrm{mg} / \mathrm{kg} /$ day and $200 \mathrm{mg} / \mathrm{kg} /$ day, $\mathrm{p}<0.01 ;$ †† = curcumin $50 \mathrm{mg} / \mathrm{kg} /$ day $\times$ curcumin $200 \mathrm{mg} / \mathrm{kg} /$ day for two and four weeks, $p<0.01$ ). Student t test. 


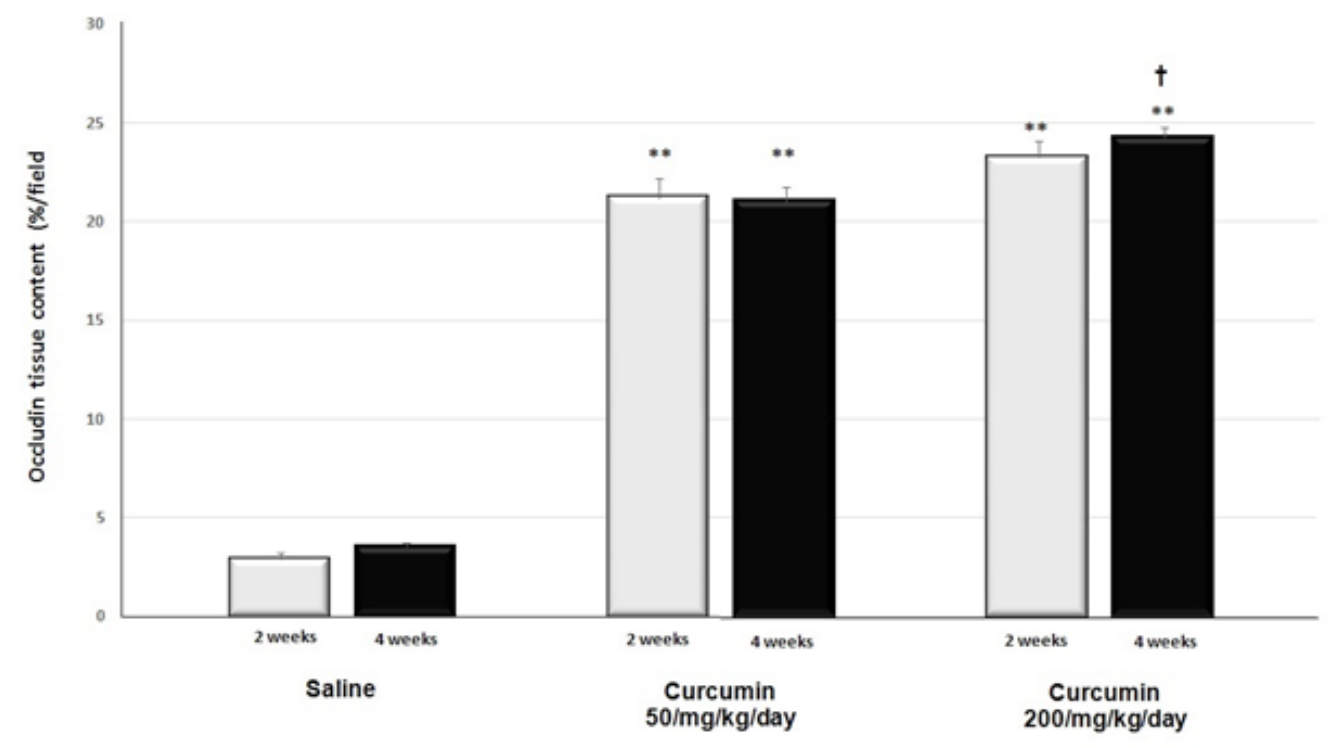

Figure 5 - Colonic mucosa: A) Colonic mucosa devoid from fecal stream submitted to intervention with saline. Lack of tissue expression of occludin in cells of colonic epithelium $(\mathrm{IH}-\mathrm{x} 400)$. B) Colonic mucosa devoid from the fecal stream submitted to intervention with curcumin at concentration of $200 \mathrm{mg} / \mathrm{kg} /$ day) showing presence of occludin in apical and basolateral membranes of the cells of the colonic epithelium (HE-x400).

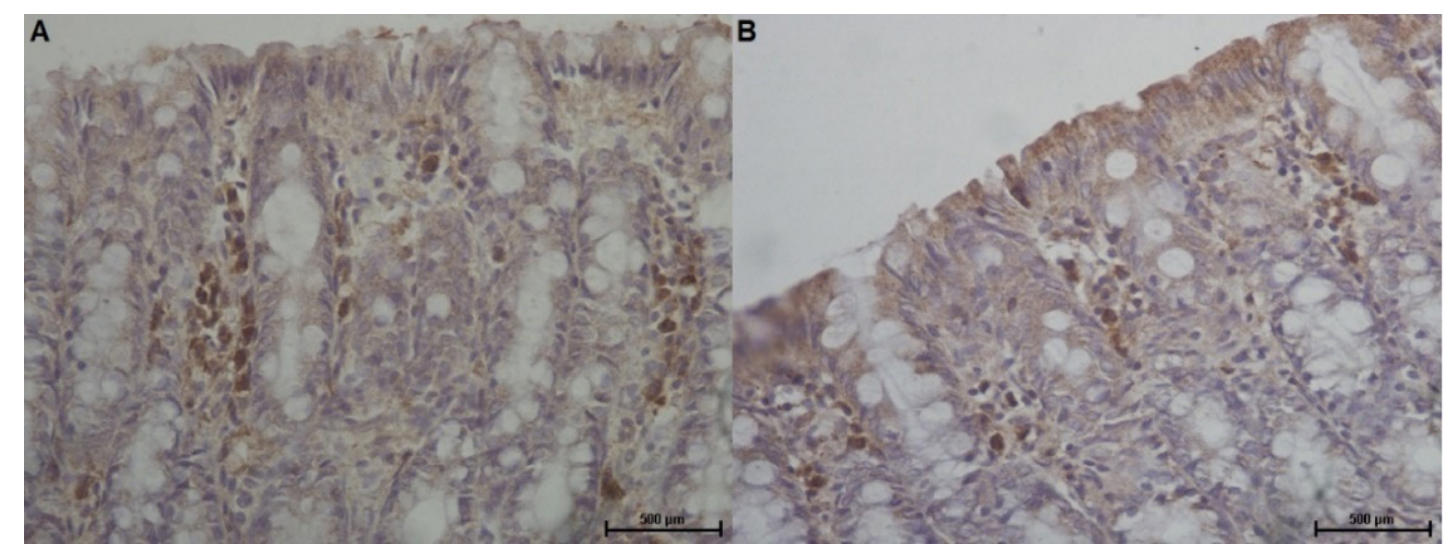

Figure 6 - Tissue content of occludin in colon segments without fecal stream after irrigation with saline, curcumin (50 mg / kg/ day) and curcumin (200 mg $/ \mathrm{kg} /$ day) for 2 and 4 weeks. ${ }^{* *}=$ saline $\times$ curcumin $50 \mathrm{mg} / \mathrm{kg} /$ day and $200 \mathrm{mg} / \mathrm{kg} / \mathrm{day}, \mathrm{p}<0.01$; $\dagger=$ curcumin $50 \mathrm{mg} / \mathrm{kg} /$ day $\times$ curcumin $200 \mathrm{mg} / \mathrm{kg} /$ day after four weeks, $\mathrm{p}<0.05$ ). Student t test.

\section{- Discussion}

The colonic epithelium is formed by a singlecell layer composed of different subtypes of specialized intestinal cells ${ }^{1}$. The cells of colonic epithelium must sense and respond appropriately to the constant immunological challenge of the colonic luminal contents and, at the same time, needs to allow absorption of water, nutrients and molecules important for cellular energy metabolism ${ }^{21}$. Intercellular adhesion in colonic mucosa is maintained by 
TJs, AJs and, gap junctions. TJs are the most apical component of the IJs and provide the most efficient form of cell-cell adhesion in gastrointestinal epithelium ${ }^{21}$. TJs connect adjacent enterocytes together to determine a controlled paracellular permeability through the lateral intercellular space ${ }^{22}$. Increasing importance is being attributed to TJs in mechanisms of epithelial cell proliferation, production of mucus layer covering the luminal surface of the epithelium, recognition of pathogens, cell survival, apoptosis and production of antimicrobial peptides to ensure effective immunity cell differentiation ${ }^{22}$. TJs is comprised of multiple proteins such claudins family, occludin, tricellulin, and junctional adhesion molecule ${ }^{11}$. The intracellular portions of these transmembrane proteins interact with cellular cytoplasmic proteins, including zonula occludens $^{23}$. These proteins also connect with actin and myosin anchoring the TJs to the cells cytoskeleton maintaining the colonic epithelium architecture. Claudins' family proteins appears to be the most important protein of the TJs. Among the claudins that tighten the paracellular barrier of the gastrointestinal tract are claudin-1, -3, -4, -5 , and -8 . These proteins have their highest expression in the colon and it follows that the colon has the highest epithelial resistance ${ }^{23,24}$. The exact barrier function of occludin is not completely understood but studies have shown that it has to be present in the TJs strands and to have a functional role in the connection between the intracellular filaments forming proteins claudin and the cytoskeleton ${ }^{24}$.

Defective intestinal epithelial TJs barrier has been postulated to be an important pathogenic mechanism leading to the increase in intestinal antigenic penetration and subsequent development of intestinal inflammation ${ }^{22}$. Studies have showing that altered expression and structural changes of the intestinal TJs proteins are closely associated with the development of IBD and $\mathrm{CDC}^{11,25,26}$. Modification on TJs leads to the loss of epithelial barrier function induces epithelial damage and alter the intestinal epithelial permeability ${ }^{11}$.

This epithelial barrier dysfunction increased uptake of antigens and toxins from the intestinal lumen and can exacerbate the inflammatory process, ending up in a vicious circle. Thus, the dysfunction of the epithelial barrier is a perpetuating principle during colonic mucosa inflammation. VFAs, mainly butyrate at low concentration, can increase the tissue expression of TJs proteins ${ }^{27}$. Since epithelial TJs are important in the maintenance of barrier function, changes in usual supply of butyrate may lead to the breakdown of this important mechanism of intercellular adhesion proteins allowing the passage of bacteria's toxins and proinflammatory molecules from the colonic lumen into the submucosa and systemic circulation ${ }^{27}$.

Studies have demonstrated the importance of VFAs in the prevention and treatment of patients with IBD and $\mathrm{CDC}^{5,28}$. VFAs can suppress the activation of the nuclear factor kappa B (NF-KB) that controls the expression of genes encoding proinflammatory citokines, COX-2, inducible NO synthase, and adhesion molecules ${ }^{27}$. Butyrate alone can contribute to about $5-15 \%$ of the total caloric requirements of humans and exerts potent effects on different colonic mucosal function such as reinforcing various components of the epithelial barrier, reducing the inflammation and decreasing oxidative stress ${ }^{27}$. However, the mechanisms by which butyrate reduces tissue oxidative stress are still poorly understood. It has been demonstrated dietary supplementation of VFAs reduces the levels of neutrophil infiltrate and restores the tissue concentration of glutathione an important component of the colonic antioxidant system ${ }^{27}$.

The diversion of the fecal stream prevents the passage of VFAs through the 
excluded segment and epithelial cells deprived of their main nutritional fuel and begin to use the glutamine, as an alternative energy source ${ }^{4,7}$. However, glutamine seems to be unable to provide all of the energy necessary to sustain the metabolism of the colonic epithelial cells, causing significant changes in the mitochondrial oxidative metabolism of the respiratory chain of these cells $s^{4}$. It has been demonstrated that $70 \%$ of the oxygen consumption in colonic cells comes from the $\beta$-oxidation of VFAs, particularly butyrate ${ }^{29}$. Butyrate can improve the inflammatory activity in IBD and may contribute to the restoration of the TJs barrier by affecting the expression of claudin-3, occludin, cingulin, and zonula occludens proteins (ZO-1, ZO-2) via inhibited release of TNF- $\alpha$ and interleukin 13 and inhibition of the transcription factor NF- $\kappa B$. The normal supply of VFAs can reduce the epithelial damage caused by oxidative stress by increase the amount of glutathione peroxidase (GSH), one of the most important antioxidant system presents in colonic mucosa ${ }^{30}$. Butyrate also decreases neutrophil infiltration and improves healing of damaged colonic mucosa ${ }^{3}$. It is an important source of fuel for colonocytes, and a diminished $\beta$-oxidation of butyrate, meaning an energy deficiency syndrome, has been associated with development of ulcerative colitis and $\mathrm{CDC}^{28,31}$. Experimental studies showed that diversion of the fecal stream leads to modifications of metabolism of the colonic epithelial cells that begin to produce large amounts of OFR ${ }^{4,8,10}$.

In previous study, we showed that the deficiency in the VFAs supply modifies the tissue content claudin-3 and occluding, the main proteins constituents of the TJs ${ }^{11}$. We verify that the tissue content of claudin-3 in colonic segments without fecal transit revealed $25.5 \%$, $48.8 \%$ and $48.3 \%$ content reductions after six, 12 and 18 weeks, respectively ${ }^{11}$. Similarly, we also find reduction in tissue content of occludin in colonic mucosa devoid of the fecal stream in order of $18 \%, 54.5 \%$ and $48.6 \%$ in six, 12 and 18 weeks, respectively ${ }^{11}$. Likewise, the reduction in tissue content of both proteins was found to be inversely related to the inflammatory intensity and directly related to the tissue levels of tissue oxidative stress. These results suggest that in colonic mucosa without VFAs supply, the degree of inflammation tends to intensify and the content of claudin- 3 and occludin tends to reduce. These findings raise the possibility that overproduction of OFR resulting from mitochondrial dysfunction, due to lack of supply of VFAs, may damage TJs by reducing the tissue content of claudin-3 and occludin. This hypothesis is supported by other studies of our group that have analyzed the protein components of AJs (E-cadherin and $\beta$-catenin) in an experimental model of CDC and showed that the levels of both proteins decreased with the time of fecal diversion and was correlated with overproduction of OFR by cells of colonic mucosa devoid from fecal stream ${ }^{8-10}$. This evidence reinforces the importance of VFAs in the maintenance the integrity of both TJs and AJs in experimental CDC.

Studies have shown that the application of enemas containing substances with antioxidant activity in colonic segments devoid from the fecal stream can protect and preserve the colonic epithelial barrier integrity ${ }^{12,13,32}$. zThese substances can reduce the epithelial damage, improve the inflammation and increase the mucous layer that recovers the colonic mucosa devoid of the fecal stream ${ }^{1-3}$. Curcumin has been used as a substance for the prevention and treatment of many organ and tissue disorders, most of which are associated with inflammation and oxidative stress ${ }^{33,34}$. Curcumin alleviates oxidative stress due to its chemical structure functioning as a natural free radical scavenger reducing the inflammatory process in chronic diseases and regulates inflammatory and pro-inflammatory pathways 
related with colitis ${ }^{14,34}$. The substance was able to scavenger, in a concentration-dependent way, superoxide anion, hydroxyl radical, peroxyl radical, singlet oxygen, peroxynitrite anion, hypochlorous acid and hydrogen peroxide. Curcumin can decrease the release of different interleukins through NF-KB and it is associate with amelioration of macroscopic and microscopic colitis sores, reduce the mieloperoxidase activity, and decrease the tissue levels of malondialdeyde an important marker of oxidative stress ${ }^{17}$. NF-KB is a key signaling molecule in the elaboration of the inflammatory response in IBD. It is a key target for numerous anti-inflammatory therapies, which is involved in the overproduction of OFR, cytokines, chemokines and NF-KB pathway has been identified as a mediator of inflammation and therefore serves as an important target for drug development and discovery. Curcumin can modulate immune response through the inhibition of the key oxidative stress represents by NF-KB ${ }^{33}$. Study have shown that curcumin is able to prevent the decrease of tissue expression of occludin, claudin, $\beta$-catenin and E-cadherin resulting of oxidative stress ${ }^{35}$. Recently, our group evaluating the effects of application of enemas containing oily extract of curcumin in a CDC experimental model showed that the substance was able to decrease the degree of epithelial inflammation and reduce the levels of neutrophil infiltrate assessed by the tissue expression of the myeloperoxidase ${ }^{20}$.

The result of this study seems to confirm the beneficial effects of the application of enemas containing oily extract of curcumin in the preservation of the tissue content of claudin-3 and occludin. We verify that the animals submitted to daily applications of daily enemas with curcumim showed higher tissue content of claudin-3 and occludin. When we compare the tissue content of claudin- 3 in the animals of the control group with those undergoing to intervention with curcumin, we found that animals that received enemas with curcumin showed greater content of claudin-3 those subjected to intervention with saline. Animals that received enemas containing higher concentrations of curcumin (200mg / kg / day) for four weeks the tissue content of claudin-3 had its highest values. These findings suggest that the effects of curcumin on claudin-3 tissue content is dependent on the concentration used and the time of intervention. The evaluation of the tissue content of occludin showed similar results. The daily application of enemas with oily extract of curcumin significantly increased the tissue content of occludin and the higher values were detected in animals subjected to intervention with higher concentrations of curcumin (200mg / kg / day) for four weeks. Previous studies using cell culture showed that curcumin prevents leptin-impaired TJs function in intestinal cells and in colonic epithelial cells against oxidative stress with $\mathrm{H}_{2} \mathrm{O}_{2}$-induced disruption of TJs ${ }^{36,37}$.

The results of this study showed that the application of enemas with oily extract of curcumin is an effective therapeutic strategy to improve de inflammatory process and to preserve the tissue content of claudin- 3 and occludin in an experimental model of CDC. It is probably that the mechanism of action of curcumin in colonic mucosa lacking of normal supply of VFAs is related to its ability to remove excess of OFR produced by cells of the intestinal epithelium devoid from the fecal stream. Clinical studies in patients with CDC are still required to propose this therapeutic strategy in clinical practice.

\section{- Conclusion}

The application of enemas with curcumin reduces inflammation and preserves the tissue content of the proteins claudin- 3 and occludin in the colonic mucosa devoid from the fecal stream. 


\section{References}

1. Pereira JA, Rodrigues MR, Sato DT, Silveira Junior PP, Dias AM, Silva CG, Martinez, CAR. Evaluation of sucralfate enema in experimental diversion colitis. J Coloproctol (Rio J.). 2013 Dez; 33(4):182-90. doi: 10.1016/j.jcol.2013.08.005.

2. Chaim FM, Sato DT, Rodrigues MR, Dias AM, Silveira Júnior PP, Pereira JA, Martinez CA. Evaluation of the application of enemas containing sucralfate in tissue content of neutral and acid mucins in experimental model of diversion colitis. Acta Cir Bras. 2014 Sep; 29(9):544-52. doi: 10.1590/ S0102-8650201400150001.

3. Bonassa CEG, Pereira JA, Campos FGCM, Rodrigues MR, Daniela TS, Chaim FDM, Martinez CAR. Tissue content of sulfomucins and sialomucins in the colonic mucosa, without fecal stream, undergoing daily intervention with sucralfate. Acta Cir Bras. 2015 May;30(5):328-38. doi: 10.1590/ S0102-865020150050000004.

4. Martinez CAR, Ribeiro $M L$, Gambero $A$, Miranda DDC, Pereira JA, Nadal SR. The importance of oxygen free radicals in the etiopathogenesis of diversion colitis in rats. Acta Cir Bras. 2010 Oct;25(5):387-95. doi: 10.1590/S0102-86502010000500002.

5. Cook SI, Sellin JH. Review article: short-chain fatty acids in healthy and disease. Aliment Pharmacol Ther. 1998 Jun;12(6):499-507. PMID: 9678808.

6. Glotzer DJ, Glick ME, Goldman H. Proctitis following diversion of fecal stream. Gastroenterology. 1981 Mar;80(3):438-41. PMID: 7450438.

7. Pravda, J. Radical induction theory of ulcerative colitis. World J Gastroenterol. 2005 Apr 28;11(16):2371-84. doi: 10.3748/ wjg.v11.i16.2371.

8. Parrish AR, Catania JM, Orozco J, Gandolfi AJ. Chemically induced oxidative stress disrupts the E-cadherin/catenin cell adhesion complex. Toxicol Sci. 1999 Sep;51(1):80-6. PMID: 10496679.

9. Martinez CAR, Fabris FM, Silva CMG, Rodrigues MR, Sato DT, Ribeiro ML, Pereira JA. Oxidative stress and changes in the content and pattern of tissue expression of $\boldsymbol{\beta}$-catenin protein in diversion colitis. J. Coloproctol. (Rio J.). 2012 Dez;32(4):343-58. doi: 10.1590/S2237-93632012000400001.

10. Kadri CJ, Pereira JA, da Silva CM, Nonose $R$, Nascimento, EF, Jacomo AL, Martinez CA. E-cadherin expression in colonic mucosa with and without fecal stream. J Invest Surg. 2013 Apr;26(2):72-9. doi: 10.3109/08941939.2012.693334.

11. Martinez CA, de Campos FG, de Carvalho VR, de Castro Ferreira C, Rodrigues MR, Sato DT, Pereira JA. Claudin-3 and occludin tissue content in the glands of colonic mucosa with and without a fecal stream. J Mol Histol. 2015 Apr;46(2):183-94. doi: 10.1007/s10735-015-9610-y.

12. Caltabiano C, Máximo FR, Spadari AP, da Conceição Miranda DD, Serra MM, Ribeiro ML, Martinez CA. 5-aminosalicylic acid (5ASA) can reduce levels of oxidative DNA damage in cells of colonic mucosa with and without fecal stream. Dig Dis Sci. 2011 Apr;56(4):1037-46. doi: 10.1007/s10620010-1378-z.

13. Cunha FL, Silva CM, Almeida MG, Lameiro TM, Marques LH, Margarido NF, Martinez CA. Reduction in oxidative stress levels in the colonic mucosa without fecal stream after the application of enemas containing aqueous Ilex paraguariensis extract. Acta Cir Bras. 2011 Aug;26(4):289-96. doi: 10.1590/ S0102-86502011000400008.

14. Brumatti LV, Marcuzzi A, Tricarico PM, Zanin V, Giradelli M, Bianco AM. Curcumin and inflammatory bowel disease: potential and limits of innovative treatments. Molecules. 2014 Dec 16;19(12):21127-53. doi: 10.3390/ molecules191221127.

15. Jiang $H$, Deng CS, Zhang $M$, Xia J. Curcuminattenuated trinitrobenzene sulphonic acid induces chronic colitis by inhibiting expression of cyclooxygenase-2. World J Gastroenterol. 2006 Jun 28;12(24):3848-53. doi: 10.3748/wjg.v12.i24.3848.

16. Deguchi Y, Andoh A, Inatomi O, Yagi Y, Bamba S, Araki Y, Hata K, Tsujikawa T, Fujiyama Y. Curcumin prevents the development of dextran sulfate Sodium (DSS)-induced experimental colitis. Dig Dis Sci. 2007 Nov;52(11):2993-8. doi: 10.1007/s10620006-9138-9.

17. Topcu-Tarladacalisir Y, Akpolat $M, U z$ YH, Kizilay G, Sapmaz-Metin M, Cerkezkayabekir A, Omurlu IK. Effects of curcumin on apoptosis and oxidoinflammatory regulation 
in a rat model of acetic acid-induced colitis: the roles of c-Jun $\mathrm{N}$-terminal kinase and p38 mitogen-activated protein kinase. J Med Food. 2013 Apr;16(4):296-305. doi: 10.1089/jmf.2012.2550.

18.Singla V, Pratap Mouli V, Garg SK, Rai T, Choudhury BN, Verma P, Deb R, Tiwari V, Rohatgi S, Dhingra R, Kedia S, Sharma PK, Makharia G, Ahuja V. Induction with NCB02 (curcumin) enema for mild-to-moderate distal ulcerative colitis - a randomized, placebo-controlled, pilot study. J Crohns Colitis. 2014 Mar;8(3):208-14. doi: 10.1016/j.crohns.2013.08.006.

19. Hanai $H$, lida T, Takeuchi K, Watanabe F, Maruyama Y, Andoh A, Tsujikawa T, Fujiyama Y, Mitsuyama K, Sata M, Yamada M, Iwaoka Y, Kanke K, Hiraishi H, Hirayama K, Arai H, Yoshii S, Uchijima M, Nagata T, Koide Y. Curcumin maintenance therapy for ulcerative colitis: randomized, multicenter, double-blind, placebo-controlled trial. Clin Gastroenterol Hepatol. 2006 Dec;4(12):1502-6. doi: 10.1016/j.cgh.2006.08.008.

20. Kadri CJ, Pereira JA, Campos FG, Ortega MM, Bragion CB, Martinez CA. Anti-inflammatory effects of enemas containing an oily extract of curcumin in an experimental model of diversion colitis. Histol Histopathol. 2017 Feb;32(2):161-9. doi: 10.14670/HH-11-783.

21.Borra SK, Mahendra J, Gurumurthy P, Jayamathi lqbal SS, Mahendra L. Effect of curcumin against oxidation of biomolecules by hydroxyl radicals. J Clin Diagn Res. 2014 Oct;8(10):CC01-5. doi: 10.7860/ JCDR/2014/8517.4967.

22. Laukoetter MG, Nava P, Nusrat A. Role of the intestinal barrier in inflammatory bowel disease. World J Gastroenterol. 2008 Jan 21;14(3):401-7. doi: 10.3748/WJG.14.401.

23.John LJ, Fromm M, Schulzke JD. Epithelial barriers in intestinal inflammation. Antioxid Redox Signal. 2011 Sep;15(5):1255-70. doi: 10.1089/ars.2011.3892.

24.Zihni C, Mills C, Matter K, Balda MS. Tight junctions: from simple barriers to multifunctional molecular gates. Nat Rev Mol Cell Biol. 2016 Sep;17(9):564-80. doi: 10.1038/nrm.2016.80.

25. Saitou M, Furuse M, Sasaki H, Schulzke JD, Fromm M, Takano H, Noda T, Tsukita S. Complexphenotype of mice lacking occludin, a component of tight junction strands. Mol
Biol Cell. 2000 Dec;11(12):4131-42. PMID: 11102513.

26. Schmitz H, Barmeyer C, Fromm M, Runkel N, Foss HD, Bentzel CJ, Riecken EO, Schulzke JD. Altered tight junction structure contributes to the impaired epithelial barrier function in ulcerative colitis. Gastroenterology. 1999Feb;116(2):301-9. PMID: 9922310.

27. Hamer HM, Jonkers D, Venema K, Vanhoutvin $S$, Troost FJ, Brummer RJ. Review article: role of butyrate on colonic function. Aliment Pharmacol Ther. 2008 Jan 15;27(2):104-19. doi: 10.1111/j.1365-2036.2007.03562.x.

28.Zeissig S, Bürge IN, Günzel D, Richter J, Mankertz J, Wahnschaffe U, Kroesen AJ, Zeitz M, Fromm M, Schulzke JD. Changes in expression and distribution of claudin 2, 5 and 8 lead to discontinuous tight junctions and barrier dysfunction in active Crohn's disease. Gut. 2007 Jan;56(1):61-72. doi: 10.1136/gut.2006.094375.

29. Oliveira-Neto JP, Aguilar-Nascimento JE. Intraluminal irrigations with fibers improves inflammation and atrophy in diversion colitis. Nutrition. 2004 Feb;20(2):197-9. doi: 10.1016/j.nut.2003.10.006.

30. Chapman MA, Grahn MF, Boyle MA, Hutton $M$, Rogers J, Williams NS. Butyrate oxidation is impaired in the colonic mucosa of sufferers of quiescent ulcerative colitis. Gut. 1994 Jan;35(1):73-6. PMID: 8307454.

31. Tedelind S, Westberg F, Kjerrulf M, Vidal A. Anti-inflammatory properties of the shortchain fatty acids acetate and propionate: a study with relevance to inflammatory bowel disease. World J Gastroenterol. 2007 May 28;13(20):2826-32. doi: 10.3748/wjg.v13. i20.2826.

32. Martinez CA, de Almeida MG, da Silva CM, Ribeiro ML, da Cunha FL, Rodrigues MR, Sato DT, Pereira JA. Enemas with $\mathrm{N}$-acetylcysteine can reduce the level of oxidative damage in cells of the colonic mucosa diverted from the faecal stream. Dig Dis Sci. 2013 Dec;58(12):3452-9. doi: 10.1007/s10620013-2768-9.

33. Mouzaoui S, Rahim I, Djerdjouri B. Aminoguanidine and curcumin attenuated tumor necrosis factor (TNF)- $\alpha$-induced oxidative stress, colitis and hepatotoxicity in mice. Int Immunopharmacol. 2012 Jan;12(1):302-11. doi:10.1016/j. intimp.2011.10.010. 
34. Nonose N, Pereira JA, Machado PR, Rodrigues MR, Sato DT, Martinez CA. Oral administration of curcumin (Curcuma longa) can attenuate the neutrophil inflammatory response in zymosan-induced arthritis in rats. Acta Cir Bras. 2014 Nov;29(11):727-34. doi: 10.1590/S0102-86502014001800006.

35.Trujillo J, Molina-Jijón E, Medina-Campos ON, Rodríguez-Muñoz R, Reyes JL, Loredo ML, Barrera-Oviedo D, Pinzón E, Rodríguez-Rangel DS, Pedraza-Chaverri J. Curcumin prevents cisplatin-induced decrease in the tight and adherens junctions: relation to oxidative stress. Food Funct. 2016 Jan;7(1):279-93. doi: 10.1039/c5fo00624d.

36. Kim CY, Kim KH. Curcumin prevents leptininduced tight junction dysfunction in intestinal Caco-2 BBe cells. J Nutr Biochem. 2014 Jan;25(1):26-35.doi: 10.1016/j. jnutbio.2013.08.011.

37. Wang N, Wang G, Hao J, Ma J, Wang Y, Jiang $X$, Jiang $H$. Curcumin ameliorates hydrogen peroxide-induced epithelial barrier disruption by upregulating heme oxygenase- 1 expression in human intestinal epithelial cells. Dig Dis Sci. 2012 Jul;57(7):1792-801. doi: 10.1007/s10620012-2094-7

\section{Correspondence:}

Carlos Augusto Real Martinez

Rua Rui Barbosa, 255/32

09190-370 Santo André - SP Brasil

caomartinez@uol.com.br

Conflict of interest: none

Financial source: FAPESP (Project Nº. 2010/12492-7)
Received: Sep 19, 2016

Review: Nov 18, 2016

Accepted: Dez 20, 2016

${ }^{1}$ Research performed at Laboratory of Medical Investigation, Universidade São Francisco (USF), Bragança Paulista-SP, Brazil. 